\begin{tabular}{c|c|c}
\hline \hline & CLIMATE RESEARCH & Published July 4 \\
Vol. 17: 73-82, 2001 & Clim Res & \\
\hline
\end{tabular}

\title{
Cod and climate variability in the Barents Sea
}

\author{
Joachim W. Dippner ${ }^{1, *}$, Geir Ottersen ${ }^{2, * *}$ \\ ${ }^{1}$ Institut für Ostseeforschung, Seestr. 15, Warnemünde, 18119 Rostock, Germany \\ ${ }^{2}$ Institute of Marine Research, Nordnesgaten 50, PO Box 1870, Nordnes, Bergen 5817, Norway
}

\begin{abstract}
Interannual variability of temperature in the Kola section (Barents Sea) and the abundance as 0-group (age $5 \mathrm{mo}$ ) and recruits (age $3 \mathrm{yr}$ ), spawning stock biomass, and survival of ArctoNorwegian cod in the Barents Sea were related to climate variability using a multivariate regression model. The results show that in the Barents Sea the temperature anomalies are significantly and highly correlated to climate variables such as large-scale sea-level pressure fields and the North Atlantic Oscillation index. A significant and high correlation was detected between the temperature in the Barents Sea and both the 0-group index and recruitment of Arcto-Norwegian cod. A phase lag of $2 \mathrm{yr}$ appears in recruitment. The high model skill and excellent correlation indicate that it is possible to predict the future development of Arcto-Norwegian cod stocks from climate-change scenarios.
\end{abstract}

KEY WORDS: Climate variability $\cdot$ Cod recruitment $\cdot$ Barents Sea $\cdot$ Multivariate statistics

\section{INTRODUCTION}

Marine ecosystems vary extensively in time and space and are influenced by physical forcing, biological interaction and anthropogenic signals (Cushing \& Dickson 1976, Cushing 1978, 1996). An important aspect of interannual variability is the extent to which it is related to environmental fluctuations. It is well documented that large-scale climate phenomena can influence regional environmental conditions. While small-scale processes govern the details of air-sea interaction, large-scale phenomena ultimately drive the temporally and spatially averaged exchanges of heat, momentum and water vapor (Namias \& Cayan 1981). The dominant signal of interannual variability in atmospheric circulation for northern and central Europe is the North Atlantic Oscillation (NAO) (Walker \& Bliss 1932, Barnston \& Livzey 1987, Lamb \& Peppler 1987, Kushnir \& Wallace 1989, Hurrell 1995). The NAO index, the difference in the sea-level air pressure (SLP)

\footnotetext{
*E-mail: dippner@io-warnemuende.de

${ }^{* *}$ Present address: Division of Zoology, Department of Biology, University of Oslo, Kristine Bonnevies Hus, Moltke Moesvei, PO Box 1050, Blindern, Oslo 0316, Norway
}

anomalies between the Azores high and the Icelandic low, has been linked to a number of climatic factors throughout the North Atlantic region including speed and direction of the prevailing westerly winds and high atmospheric and sea temperatures in western Europe (Fromentin \& Planque 1996, Dickson 1997, 1999). The NAO is the only atmospheric mode that is robustly present in every month of the year. It is most pronounced in amplitude and areal coverage during wintertime, the season of strongest pressure gradients and interannual variability (Moses et al. 1987, Cayan 1992), and it accounts for more than one-third of the total variance in SLP (Marshall \& Kushnir 1997).

It is generally accepted that climate variability and fishing are the 2 most important factors regulating the size of fish populations. Many attempts have been made to explain fish recruitment success or failure by environmental fluctuations. Actually, the search for environmental predictors of recruitment is at least a century old (Cushing 1982). However, it must be noted that many of the initially statistically significant correlations between environment and fish recruitment have been shown to break down when tested with new data (Myers 1998). This should not be taken as evidence for climate fluctuations not influencing recruit- 


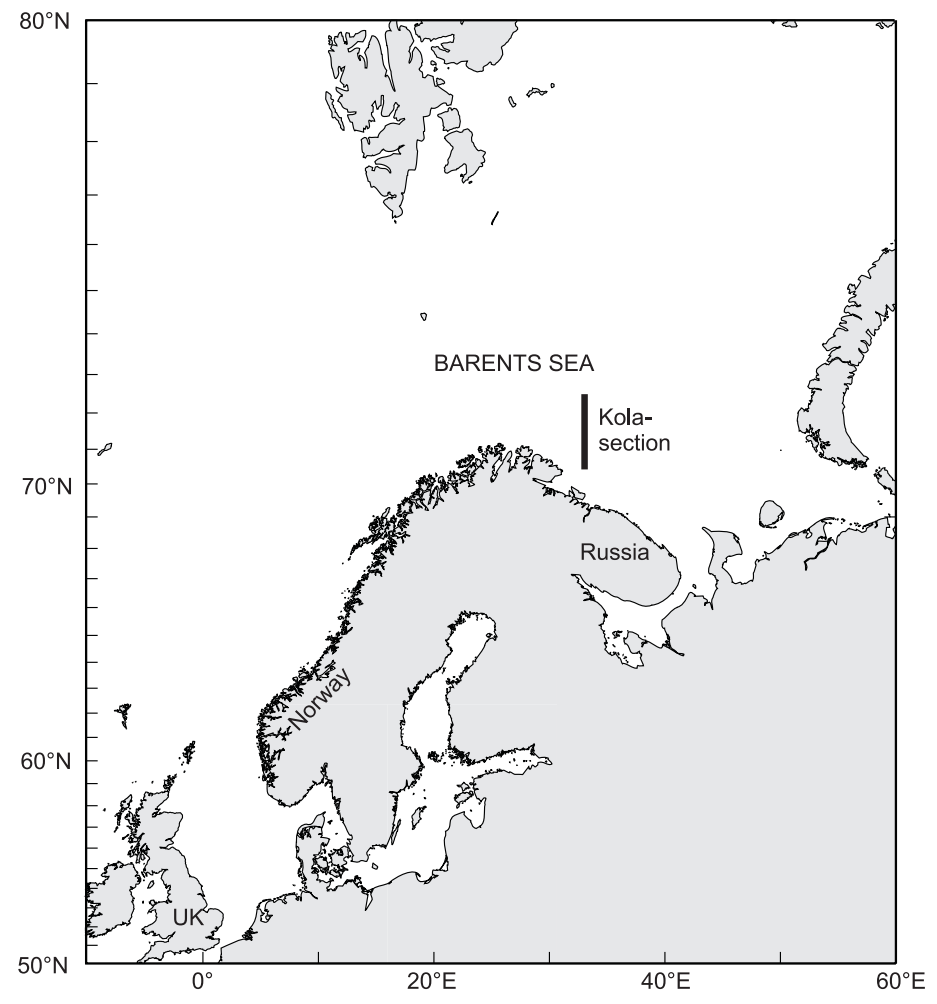

Fig. 1. Northern Europe with the Barents Sea and the location of the hydrographic Kola Section indicated

ment, but that the nature of the relations in many cases vary with time and are not fully understood. For populations close to the northern limit of a species' range, temperature-recruitment relations seem to be consistently positive for fish in general (Myers 1998) and cod Gadus morhua L. in particular (Ottersen 1996, Planque \& Fredou 1999).

The Barents Sea is an open arcto-boreal shelf sea. Temperature conditions in the southern and central Barents Sea, the area inhabited by the Arcto-Norwegian cod, are to a large degree determined by the quality and quantity of the Atlantic water flowing in from the southwest. Processes in the Barents Sea such as water cooling and ice formation (Midttun 1990) and the narrow and strong coastal current entering the Barents Sea close to the Norwegian coast are also important (Loeng et al. 1995a). The landings of Arcto-Norwegian cod have fluctuated considerably throughout the last decades (Nakken 1994, Ottersen 1996). The ratio between numbers of high to low year class strength is about 15 if evaluated at the 3 yr stage (Ottersen 1996), and as high as 70 for early juveniles (Ottersen \& Sundby 1995). Several previous authors have suggested that interannual variation in Barents Sea temperature accounts for much of the fluctuations in cod recruitment (Saetersdal \& Loeng 1987, Loeng 1989,
Ellertsen et al. 1989, Ottersen et al. 1994, Ottersen \& Sundby 1995).

In this paper, we investigate how climate fluctuations on the scale of the North Atlantic affects interannual variability in sea temperature in the Barents Sea (Fig. 1) and ultimately determines the recruitment to the northernmost and potentially largest stock of true cod in the world (Nakken 1994), the Arcto-Norwegian or Northeast Arctic cod.

\section{METHOD}

The method applied is based on the statistical downscaling model of von Storch et al. (1993) and von Storch (1995). The idea is to correlate potential climate predictor variables with regional observations via a multivariate model and to look for high correlations. The basic concept is sketched in Fig. 2. The predictands are the anomalies (against the seasonal cycle) of the regional data sets. The potential predictors are the anomalies of climate observations. A possible time lag between the signals in climate and the local variables is taken into account. In a second step, the combinations with the highest skills are selected and tested for their statistical significance. Finally, the physical and biological plausibility of the remaining combination has to be evaluated.

Information from fields of climate predictors and regional predictands can be related to each other in the following way: Firstly, empirical orthogonal functions (EOFs, also known as principal components) of the predictors and predictands are calculated. Thus, the major part of the variance from a multidimensional vector is concentrated in a few new dimensions, the leading eigenmodes. The advantage is to keep the dimensionality of the model low. Consider a global variable, e.g. SLP, which is a function of space and time, $\vec{G}(r, t)$ with $\left\{r=1, \ldots, R ; t=1, \ldots, T_{1}\right\} . R$ are the stations of observations and $T_{1}$ the numbers of observations. From this global variable, anomalies $\vec{G}^{\prime}(r, t)$ are constructed by subtracting the trend and the seasonal cycle. These anomalies are expanded into a finite series of EOFs:

$$
\vec{G}^{\prime}(r, t)=\sum_{i=1}^{K} \vec{\Gamma}_{i}^{\mathrm{EOF}}(r) \gamma_{i}^{\mathrm{EOF}}(t)+\text { Noise }
$$

where $\vec{\Gamma}_{i}^{\mathrm{EOF}}(r)$ is the $i$ th EOF pattern fixed in space and $\gamma_{i}^{\mathrm{EOF}}(t)$ is the corresponding time coefficient. The EOFs are the eigenvectors of the covariance matrix of $\vec{G}^{\prime}(r, t)$. A special property of EOFs is that the variance $\operatorname{Var}\left[\vec{G}^{\prime}(r, t)-\vec{\Gamma}_{i}^{\mathrm{EOF}}(r) \gamma_{i}^{\mathrm{EOF}}(t)\right]$ is a minimum for $i=1$, and for $i>1$ it is always a minimum under the constraint that $\left[\vec{\Gamma}_{i}^{\mathrm{EOF}}(r), \vec{\Gamma}_{j}^{\mathrm{EOF}}(r)\right]=\delta_{i j}$, i.e. the EOF patterns are orthogonal to each other. Hence, it is possi- 
ble to expand the observed variable $\vec{G}^{\prime}(r, t)$ according to Eq. (1) such that the main portion of variability of $\vec{G}^{\prime}(r, t)$ is explained by the leading $K$ EOF patterns and time series, with $K \leq R$, often with $K<<R$. Depending on the examined question, the expansion according to Eq. (1) can be interpreted as a decomposition into a signal and a noise subspace. The signal subspace is spanned by the leading $K$ EOF patterns and describes the main portion of variability of $\vec{G}^{\prime}(r, t)$, which is generally variability that occurs simultaneously at all stations. The noise subspace is spanned by the trailing $R-K+1$ patterns and describes a minor part of the variability, generally station details. The same procedure is carried out for a local variable $\vec{L}(s, t)$. The amount of variance accounted for by the leading eigenmodes is given by:

$$
\eta_{\mathrm{j}}=1-\frac{\operatorname{Var}\left[\vec{G}^{\prime}(r, t)-\sum_{i=1}^{j} \vec{\Gamma}_{\mathrm{i}}^{\mathrm{EOF}}(r) \gamma_{i}^{\mathrm{EOF}}(t)\right]}{\operatorname{Var}\left[\vec{G}^{\prime}(r, t)\right]}
$$

(1)

(2)

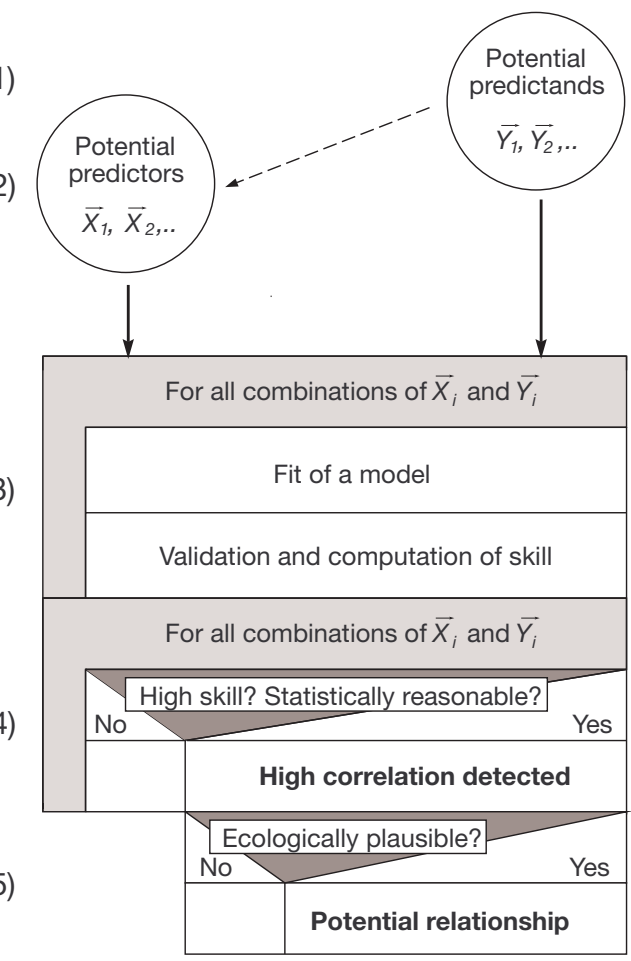

Fig. 2. Outline of method, after Kröncke et al. (1998): depending on the variables of interest (1), possible predictor variables are collected (2). One combination of predictand and predictor is selected (3) and a statistical model is fitted and validated (4). Thereafter (5), the combinations with the highest skills are selected and unreasonable combinations are excluded. Finally, the physical and biological plausibility of the remaining combinations is discussed. A combination that passes all these tests probably indicates that a causal relationship exist. The considered combinations are given in Table 1
Secondly, to find a relationship between the leading eigenmodes of the predictor and the predictand of $\dot{G}^{\prime}(r, t)$ and $L^{\prime}(s, t)$, a canonical correlation analysis (CCA) is performed between the leading eigenmodes of the climate predictor and the regional time series. The CCA combines the EOF time coefficients using weights $g_{i j}$ and $l_{i j}$ into new CCA time coefficients $\gamma_{j}^{\mathrm{CCA}}(t)$ and $\lambda_{j}^{\mathrm{CCA}}(t)$ :

and

$$
\gamma_{j}^{\mathrm{CCA}}(t)=\sum_{i=1}^{I} g_{i j} \gamma_{i}^{\mathrm{EOF}}(t)
$$

$$
\lambda_{j}^{\mathrm{CCA}}(t)=\sum_{i=1}^{I} 1_{i j} \lambda_{i}^{\mathrm{EOF}}(t)
$$

The weights are selected such that

$$
\left[\gamma_{i}^{\mathrm{CCA}}(t)_{i} \lambda_{j}^{\mathrm{CCA}}(t)\right]=\rho_{j}^{*} \delta_{i j}
$$

with $\rho_{j}$ being maximum for $j=1$. For $j>1, \rho_{j}$ is maximum under the constraint that

$$
\left[\lambda_{i}^{\mathrm{CCA}}(t), \lambda_{j}^{\mathrm{CCA}}(t)\right]=\left[\gamma_{i}^{\mathrm{CCA}}(t), \gamma_{j}^{\mathrm{CCA}}(t)\right]=\delta_{i j}
$$

With this relation, CCA patterns of the CCA-signal subspace of the global and the local variables can be constructed as

$$
\vec{G}_{S}^{\prime}(r, t)=\sum_{i=1}^{I} \vec{\Gamma}_{i}^{\mathrm{CCA}}(r) \gamma_{i}^{\mathrm{CCA}}(t)
$$

and

$$
\vec{L}_{S}^{\prime}(s, t)=\sum_{i=1}^{I} \vec{\Lambda}_{i}^{\mathrm{CCA}}(s) \lambda_{i}^{\mathrm{CCA}}(t)
$$

where the CCA-signal spaces $\dot{G}_{S}^{\prime}(r, t)$ and $\dot{L}_{S}^{\prime}(s, t)$ are subspaces of the EOF-signal spaces $\dot{G}^{\prime}(r, t)$ and $L^{\prime}(s, t)$.

Thirdly, it is now possible to estimate the predictand from predictor data. Using Eqs. (5), (7) \& (8), the estimated CCA-signal subspace of the predictand $\dot{L}^{\prime} S_{\text {est }}(s, t)$ can be regressed from predictor data as

$$
\vec{L}_{S_{\text {est }}}^{\prime}(s, t)=\sum_{i=1}^{I} \vec{\Lambda}_{i}^{\mathrm{CCA}}(s) \rho_{i} \gamma_{i}^{C C A}(t)
$$

The CCA formally reduces to a plain regression if only 1 predictor and 1 predictand are used.

Since CCA correlations are optimized with respect to the sample used, it is necessary to validate the correlation with independent data. In contrast to von Storch et al. (1993), who split the records into fit and validation periods, in this paper a cross-validation technique (Michaelsen 1987) in combination with Monte-Carlo simulations used. In the cross-validation, if $n$ time steps of data are available, $n$ models are fitted by using $n-1$ different time steps each. For each model, the $n$th step of the predictand is regressed from the predictor. Finally, the $n$ estimations are compared with the observations of the predictand. For the cross-validation all data were used and no data were discarded. 


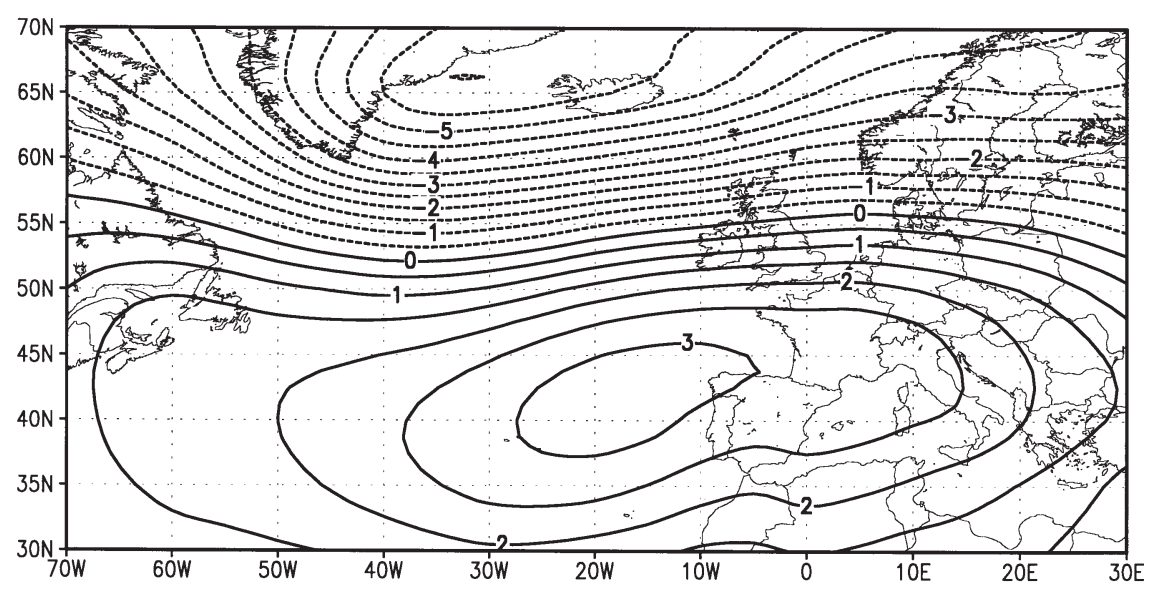

Fig. 3. First EOF of the sea-level pressure (SLP) field (DJF). The amount of variance accounted for is $43.2 \%$. Contour interval $0.5 \mathrm{hPa}$

From all combinations tested, the results with the highest skills were selected. As skill factors, correlation coefficient $\mathrm{r}$ (between the regional observations and the cross-validated estimations) and Brier-based score $\beta$ are used. The Brier-based score is defined as: $\beta=1-\sigma^{2}{ }_{e} / \sigma^{2}{ }_{0}$, where $\sigma^{2}{ }_{e}$ and $\sigma^{2}{ }_{o}$ are the variances of the error (i.e. observation minus model) and observations respectively. $\beta=1$ means that model and observation are identical, $\beta=0$ that the error of the model has the same size as the variance of the observations (Livezey 1995).

The significance level of selected results was calculated with the Monte Carlo technique. For this purpose, 1000 series of random numbers with the same statistical properties (mean, standard deviation, autocorrelation) as the EOF coefficients of the predictor were generated. For this purpose the predictor was used since climate data are much more normally distributed than biological time series. These random time series were related via CCA in the same way to the predictands as the EOF coefficients of the observed predictands were. It was checked how often $r$ and $\beta$ for the random time series reached a skill similar to the observational data.

\section{DATA}

\subsection{Climate data}

The following climate data were used as the predictor in the downscaling model:

- Data of monthly mean SLP anomalies on a $5^{\circ} \times 5^{\circ}$ grid from 1899-1996. These data were reanalysed at the National Center for Atmospheric Research (NCAR), Boulder (Trenberth \& Paolino 1980). The selected area extended from $70^{\circ} \mathrm{W}$ to $30^{\circ} \mathrm{E}$ and from $30^{\circ} \mathrm{N}$ to $70^{\circ} \mathrm{N}$.
Heyen \& Dippner (1998) have demonstrated that a climate signal can be detected more clearly if the data set is averaged over periods of several months. Therefore, a 3 mo moving-average filter has been applied to the data set. Fig. 3 shows the first EOF pattern of the winter SLP field averaged from December to February.

- The NAO index is defined as the difference between the normalized winter (October-March) SLP anomalies at Lisbon, Portugal, and Stykkisholmur, Iceland. The SLP anomalies at each station were normalized by division of each seasonal pressure by the long-term (1864-1994) mean standard deviation (Hurrell 1995). Fig. 4 shows the NAO winter index, after Hurrell (1995). The thick line is the low-pass filtered time series in which all periods less than $4 \mathrm{yr}$ are suppressed. In this paper the winter index as well as the monthly mean values are used.

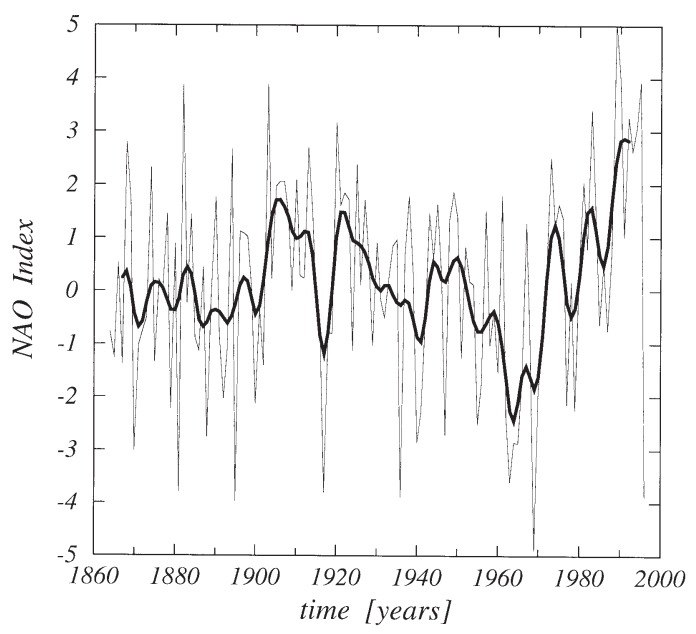

Fig. 4. North Atlantic Oscillation (NAO) winter index, after Hurrell (1995). Thick line: low-pass filtered time series 


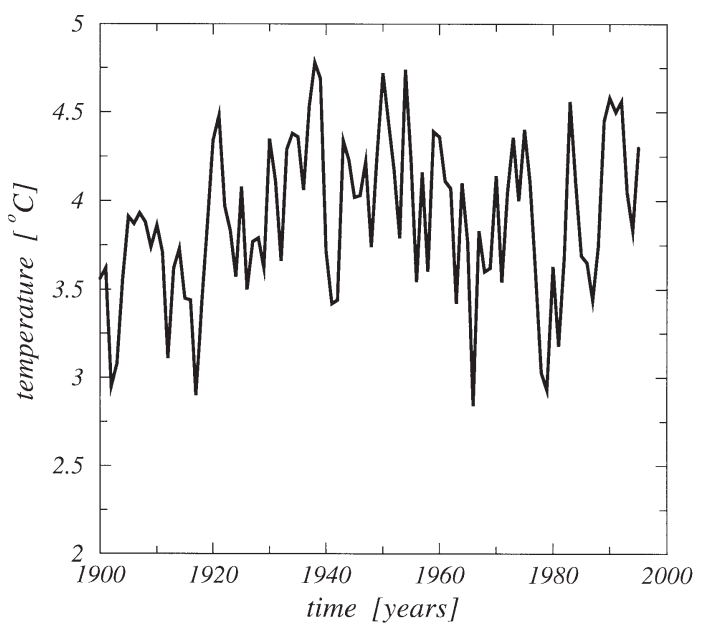

Fig. 5. Annual mean temperature of the Kola section for the period 1900-1995

\subsection{Regional data}

The following regional data were used as predictands in the downscaling model:

- Annual mean sea temperature data from the Kola section along the $33^{\circ} 30^{\prime} \mathrm{E}$ meridian from $70^{\circ} 30^{\prime} \mathrm{N}$ to $72^{\circ} 30^{\prime} \mathrm{N}$ (Fig. 5). Averages between stations and vertically over the upper $200 \mathrm{~m}$ have been made available on a quarterly basis from 1900 and as monthly means from 1921 to 1995 (Bochkov 1982, Ådlandsvik \& Loeng 1991, Tereshchenko 1996). From when the section was initiated in 1900 until 1995, it was covered more than 900 times, the only gap of significant length after 1921 being the war years of 1942-1944 (Tereshchenko 1996). The Kola section series is documented to well represent the temperature variability in the regions of the Barents Sea dominated by Atlantic water masses and is closely correlated with other time series in the area (see references in Tereshchenko 1996).

- Yearly indices for abundance of 0-group (5 mo old) Arcto-Norwegian cod for the period 1966-1998 were calculated from material gathered during Norwegian/Russian surveys in the Barents Sea between late August and early September since 1965. We use the so-called 'logarithmic indices' calculated by the method of Randa $(1982,1984)$. The gear and survey design have changed several times during the period, and we attempted to adjust the index accordingly.

- Yearly recruitment as number at age 3 (REC3), and spawning stock biomass (SSB) calculated by VPA (virtual population analysis), for the period 1947-1995 were made available by the International Council for the Exploration of the Sea (ICES). VPA is based on fisheries statistics, and the VPA estimates are the foundation of fisheries management for a number of fish stocks within the ICES area, including Arcto-Norwegian cod. VPA data for this species can be found in the annual reports of the Arctic Fisheries Working Group of ICES (ICES 1993), while VPA methodology is described in ICES (1965). It must be underlined that the 0-group data, based on dedicated scientific surveys, and the VPA data, based on catch data from fishermen, are independent. A survival index, defined as $\log (\mathrm{REC} 3$ year $n / \mathrm{SSB}$ year $n-3$ ) was calculated. This means that the number of $3 \mathrm{yr}$ old cod is related to the SSB the year they were spawned. Figs. 6 to 8 show the temporal development of 0-group abundance, REC3 and the survival index.

\section{RESULTS}

Various combinations with different lags between climate predictors and regional predictands for all seasons have been carried out. The combinations considered are given in Table 1. The strategy is firstly to find all possible correlations between climate predictors and the temperature, and secondly, to identify the connections between temperature fields and cod. As climate predictors, the NCAR reanalysed monthly mean SLP fields using the 3 dominant EOFs, the monthly mean NAO index, and the NAO winter index are used. For the Barents Sea, the monthly mean and yearly mean temperature observations in the Kola section and the 0-group index and the ICES data of recruitment, $\mathrm{SSB}$, and survival index of the Arcto-Norwegian cod are used. Table 1 displays all experiments, the predictors and predictands of the downscaling experiments, the CCA pattern of the predictor and the predictand,

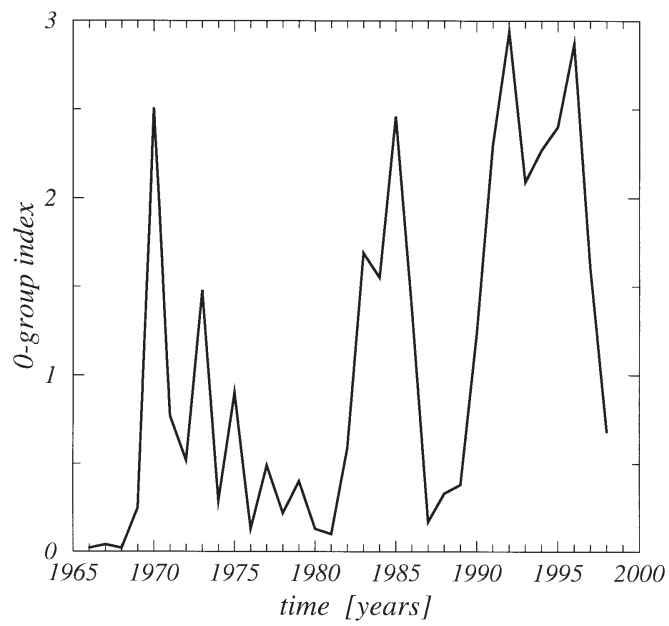

Fig. 6. Abundance as 0-group for the Arcto-Norwegian cod 


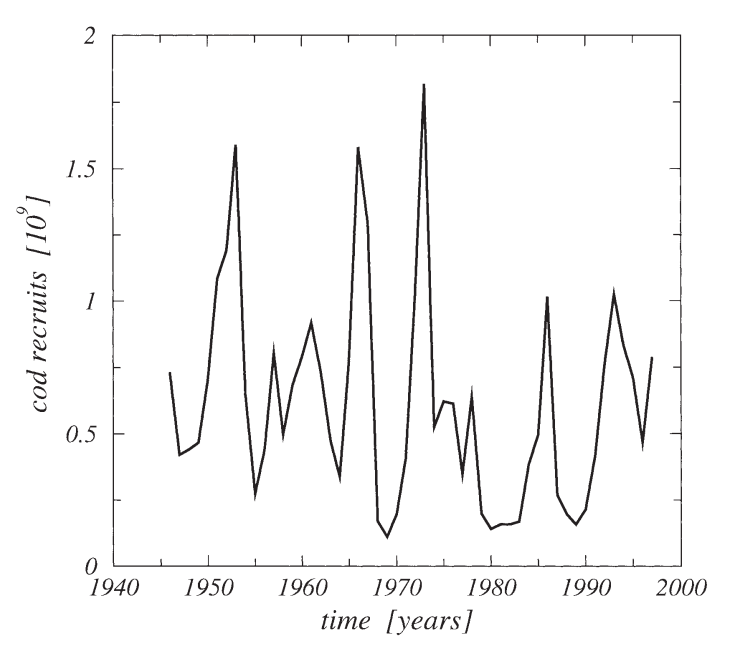

Fig. 7. Recruitment as age 3 for the Arcto-Norwegian cod

the correlation coefficient of the cross validation, the model skill, the correlation coefficient of the CCA and the $99 \%$ confidence level of the CCA.

The downscaling model shows that the temperature anomalies at the Kola section in the Barents Sea regions are highly significantly correlated to the anomalies of the climate variability of the SLP fields and the NAO index. The yearly mean temperature anomalies in the Kola section (Fig. 9) are significantly and highly correlated with the winter SLP fields (Fig. 3) and the NAO winter index (Fig. 4) in the same year. Both computations have a CCA correlation of $\mathrm{r}=0.71$. For the first computation the 3 leading EOFs of the SLP are used; these account for 43.2, 18.8 and $16.3 \%$ of the variance respectively, which means that the predictor field with 3 EOFs accounts for $78.3 \%$ of the variance in SLP. The dominant first mode in variability of the SLP is shown in Fig. 3. If monthly data of the NAO index and the Kola section are used, again significant CCA correlations exist between the NAO index in January and the tempera-

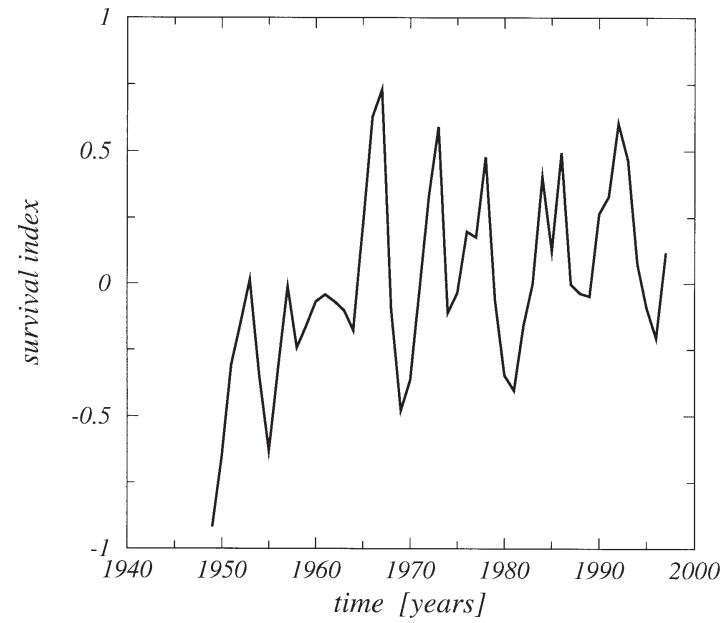

Fig. 8. Survival index defined as $\log (\mathrm{REC} 3$ year $n / \mathrm{SSB}$ year $n-3)$ for the Arcto-Norwegian cod

ture anomalies from May to September with a corresponding phase lag of 4 to $8 \mathrm{mo}$. The reason for the correlations is most likely that the Kola temperature data are averaged over the upper $200 \mathrm{~m}$ and the connected lag in the development of seasonal thermocline. As an example, Fig. 10 shows the monthly mean temperature anomaly at the Kola section in June predicted from the monthly NAO index in January. The CCA correlation is $\mathrm{r}=0.59$, and the correlation of cross validation is $r=0.58$. Table 1 shows that an anomaly in air pressure difference of $1.25 \mathrm{hPa}$ corresponds to a temperature anomaly of $0.51^{\circ} \mathrm{C}$.

The various cod time series have been analysed separately because firstly, total stock biomass and spawning stock biomass are controlled more by strong fishing pressure than by climate variability, secondly, the 0 -group data and the recruitment data of age 3 are autocorrelated and, thirdly, 0-group data (1966-1998) and recruitment data (1947-1995) have different time windows. An unlagged and statistically significant CCA correlation $(r=0.66)$ was found between Kola

Table 1. Predictors and predictands of the downscaling experiments. The CCA pattern of the predictor (P1) and the predictand (P2), the correlation coefficient of the cross validation (CC), the model skill or the Brier-based score, the correlation coefficient of the CCA, and the $99 \%$ confidence level of the CCA are shown. SLP: Sea-level pressure; DJF: December to February average using the 3 dominant EOFs; NAO12: monthly mean values of the North Atlantic Oscillation index; KOLA: yearly mean temperature values in the Kola section; KOLA12: monthly mean temperature values in the Kola section; REC3: Arcto-Norwegian cod recruitment at age 3

\begin{tabular}{|lccccccc|}
\hline Predictor & Predictand & P1 & P2 & CC & Skill & CCA & 99\% CL \\
\hline SLP(DJF) & KOLA & Fig. 3 & $0.46^{\circ} \mathrm{C}$ & 0.65 & 0.41 & 0.71 & 0.53 \\
NAO12 & KOLA12 & $1.25 \mathrm{hPa}$ & $0.51^{\circ} \mathrm{C}$ & 0.58 & 0.33 & 0.59 & 0.33 \\
KOLA & REC3 & $0.46^{\circ} \mathrm{C}$ & 0.27 & 0.59 & 0.35 & 0.61 & 0.43 \\
KOLA12 & REC3 & $0.51^{\circ} \mathrm{C}$ & 0.27 & 0.61 & 0.37 & 0.63 & 0.40 \\
KOLA & 0-group index & $0.54^{\circ} \mathrm{C}$ & 0.92 & 0.64 & 0.40 & 0.66 & 0.52 \\
\hline
\end{tabular}




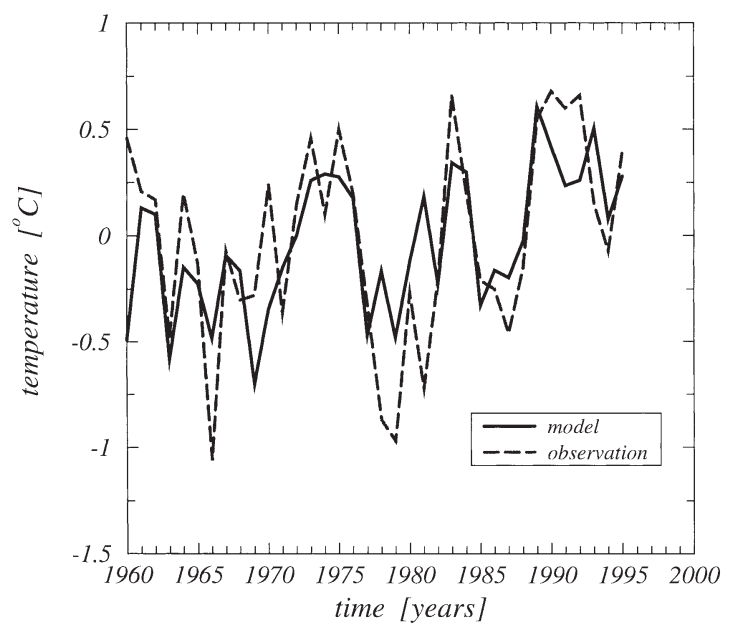

Fig. 9. Annual mean temperature anomaly in the Kola section predicted from the winter SLP field using the 3 leading EOFs. The correlation of cross validation is 0.68 , and the model skill $\beta=0.42$

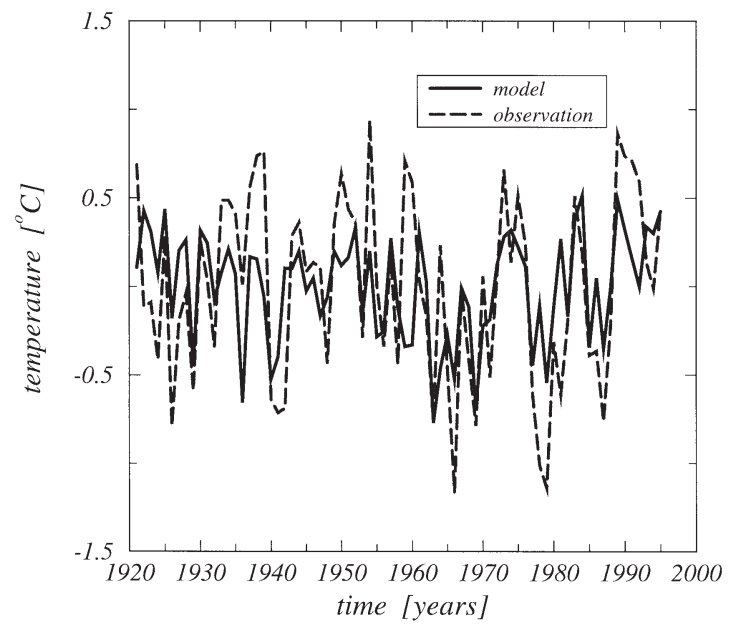

Fig. 10. Monthly mean temperature anomaly in the Kola section in June predicted from the monthly NAO index in January for the period 1921-1995. The correlation of cross validation is 0.58 , and the model skill $\beta=0.33$

section temperature, used as predictor, and the number of 0-group cod (Fig. 11). No correlations have been found between predictor fields and total stock biomass, spawning stock biomass, catch data, or survival index. Two separate analyses, one using the monthly mean and the other the yearly mean Kola temperatures, gave maximum CCA correlations with REC3 at a phase lag of $2 \mathrm{yr}$ (Fig. 12). The correlation is in the same range for both runs $(\mathrm{r}=0.61$ and 0.63$)$, and a positive temperature anomaly on the order of $0.5^{\circ} \mathrm{C}$ corresponds to a positive anomaly in cod recruitment. All CCA correlations displayed in Table 1 are significant with respect

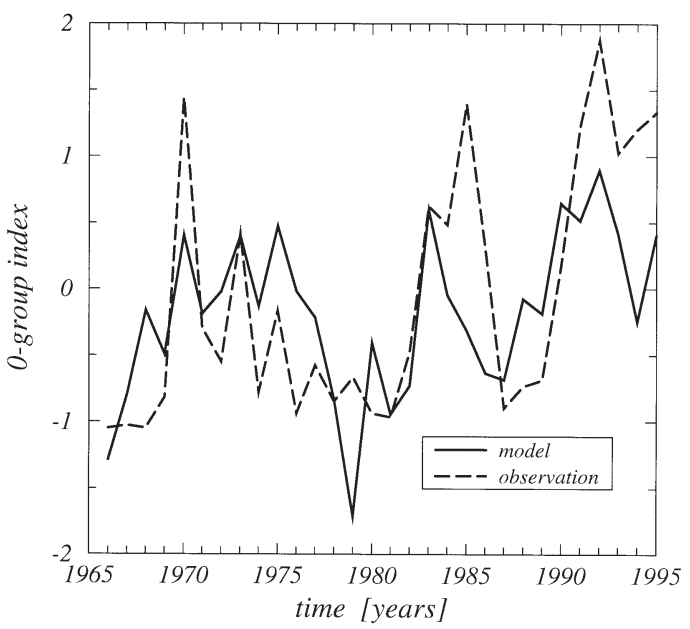

Fig. 11. Abundance as 0-group of Arcto-Norwegian cod predicted from Kola section temperature. The correlation of cross validation is 0.64 , and the model skill $\beta=0.40$

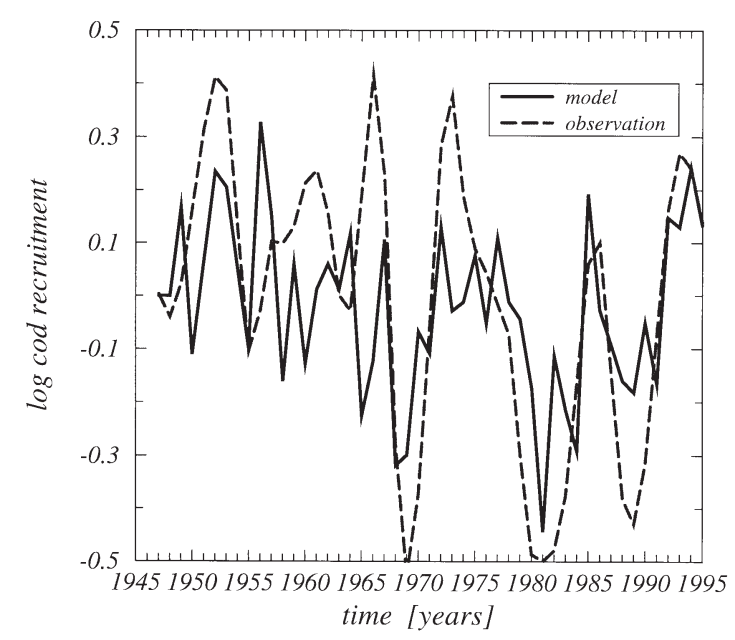

Fig. 12. Cod recruitment (REC3) in the Barents Sea predicted from the monthly mean Kola section temperature in January, $2 \mathrm{yr}$ before. The correlation of cross validation is 0.61 , and the model skill $\beta=0.37$

to the $99 \%$ confidence level. The approach to directly combine climate predictor fields (SLP or NAO index) with fish data failed: no direct correlations were found. The same result was obtained with a similar technique by Sirabella et al. (2001) using rotated EOF analysis.

\section{DISCUSSION}

Influence on regional NE Atlantic ocean climate by large-scale atmospheric forcing has already been suggested by Izhevskii (1964), who argued for what he 
called a monophasic form of fluctuation throughout the Gulf Stream system (i.e. no time lag in water temperature fluctuations from the Florida Current to the Barents Sea). More recent studies have demonstrated that much of the decadal variability in North Atlantic seasurface temperature (SST) can be explained as a local oceanic response to atmospheric variability (Deser \& Blackmon 1993, Battisti et al. 1995, Houghton 1996). The response of SST to the SLP fields and the NAO index is positive in the Norwegian Sea (Ådlandsvik \& Loeng 1991), the North Sea (Becker \& Pauly 1996, Dippner 1997a), the Baltic Sea (Dippner \& Ikauniece unpubl.) and more or less on the whole northwest European Shelf (Kawamura 1994). In addition, in the Barents Sea, the interannual variability of temperature is climate controlled, which has consequences for the functioning of the marine ecosystem.

Ådlandsvik \& Loeng (1991) showed, for the period 1970-1986, that a substantial part of the variability in the volume flux of Atlantic water to the Barents Sea was determined by atmospheric forcing. Furthermore, changes in Barents Sea temperature have on some occasions been observed to occur almost simultaneously over a large area (Loeng et al. 1992). Statistical evidence for these relations has, however, been relatively weak so far, partly due to a lack of suitable time series. Our results show that there indeed is a statistically significant link between the North Atlantic winter SLP field and Barents Sea temperature. Furthermore, in addition to correlations, we present the actual anomaly to be expected in the predictand given a certain value for the predictor (Table 1). This should make our results more readily applicable in the future.

Historically the significant fluctuations in yearly landings of cod have caused considerable puzzlement and problems for fishermen, not least along the coast of northern Norway. Many imaginative causes for this great variability have been suggested, but around the beginning of the 20th century little was yet known about the reasons for fluctuations in fish stock abundance (Øiestad 1994). At this time a few scientists started a more systematic search for relations between the environment and various aspects of fish stocks in the waters surrounding Norway. Among the first to clearly formulate that there must be some kind of connection between physical conditions and fish stocks were Helland-Hansen \& Nansen (1909): 'It is to be expected that variations in the physical conditions of the sea have great influence upon the biological conditions of the various species of fishes living in the sea, and it might therefore also be expected that such variations are the primary cause of the great and hitherto unaccountable fluctuations in the fisheries. It is therefore obvious that it would be of very great importance, not only scientifically but also practically, if the relation between the variations in the physical conditions of the sea and the variations in the biological conditions of the various food fishes could be discovered.'

We found that the link between temperature and 0 -group abundance is unlagged (Fig. 11), while the highest correlation between annual mean temperature and REC3 has a time-lag of 2 to 3 yr (Fig. 12). The following argument shows that this not only supports previous knowledge, but should give new and more precise information. An early study by Hjort (1914) indicated that processes during the first stages of the cod's life to a large degree determines the strength of a year class. Several more recent studies have documented for cod in general, and the Arcto-Norwegian population in particular, that the strength of a yearclass is determined during the first $6 \mathrm{mo}$, perhaps the first year, of life (Sundby et al. 1989, Helle et al. 2000). Furthermore, a link between temperature and abundance of these small larval and juvenile cod is described by a number of authors (Saetersdal \& Loeng 1987, Ellertsen et al. 1989, Ottersen et al. 1994, Ottersen \& Sundby 1995). This is strengthened by the correlation we found between Kola section temperature and the 0-group indices. In addition, more recently it has been shown that the mean size of 0 -group cod is closely related to temperature in such a way that they are larger in warmer years. This finding is of particular interest since size as 0-group also has been documented to be a good indicator of abundance at age 3 (Loeng et al. 1995b, Ottersen \& Loeng 2000).

The above reasoning leads to 2 conclusions: (1) VPA numbers at age 3 can be used as an indicator of the number of larvae/juveniles/0-group 2 to 3 yr earlier; and (2) temperature during the early stages is highly important for determining how large the cod year-class is, both at this stage and later on. Since the Arcto-Norwegian cod have peak spawning in April, the highest correlation we find from the REC3 data actually appears between 8 mo old cod and the temperature during their first winter. Our results thus indicate that not only is temperature during the first 6 mo highly important for determining year-class strength (as indicated by the 0-groups results), but it is also important during the following months in the fish's first winter.

In a previous study using VPA data, Dippner (1997b) demonstrated that for North Sea cod the youngest age classes are highly correlated with weekly SST fields in the North Sea. The same result has been obtained using the Comprehensive Ocean Atmosphere Data Set (COADS) winter SST fields as predictor and cod recruitment as predictand (Dippner 1999). In contrast to the Arcto-Norwegian cod, the signs of the CCA pattern are different in the North Sea. A positive anomaly in SST is connected to a negative anomaly in 0-group and 1-group cod in the North Sea. A similar result was 
obtained by Svendsen et al. (1995) using a multivariate linear regression analysis. This difference in CCA patterns gives statistical support to the hypotheses that the response of cod recruitment to above-average temperature is positive among the northern, low-temperature stocks, indeterminate for stocks with an intermediate thermal habitat, and negative for southern, high-temperature stocks (Ottersen 1996, Planque \& Fredou 1999).

Our finding of a link from large-scale atmospheric forcing through sea temperature to recruitment is new. The demonstrated links between large-scale and more regional-scale climatic variability and between regional climate and cod indicate that processes on the scale of the North Atlantic basin may heavily influence the ecology of the biologically highly productive Barents Sea. Furthermore, our statistical downscaling approach allows us to extract more information from the sea-level air pressure field than from any meteorological time series available for a single location. Importantly, since several of our most significant correlations are lagged, they have predictive value. They should thus have the potential for contributing to the management of the commercially highly valuable Arcto-Norwegian cod stock.

Acknowledgements. The authors are indebted to Hauke Heyen for helpful comments during the computations. The data set of the NAO was provided by J. Hurrell (NCAR) and the cod data by K. Brander (ICES). J.W.D. was supported by the Alfred Wegener Institute, Bremerhaven, within the framework of the CLICOFI project, which is support by the European Commission's Environment and Climate Programme under contract number ENV4-CT97-0596. The project CLICOFI contributes to the ELOISE thematic network. This publication is ELOISE publication no. 172.

\section{LITERATURE CITED}

Ådlandsvik B, Loeng H (1991) A study of the climatic system in the Barents Sea. Polar Res 10:45-49

Barnston AG, Livezey RE (1987) Classification, seasonality and persistence of low-frequency atmospheric circulation patterns. Mon Weather Rev 115:1083-1126

Battisti DS, Bhatt US, Alexander MA (1995) A modelling study of the interannual variability in the wintertime North Atlantic Ocean. J Clim 8:3067-3083

Becker GA, Pauly M (1996) Sea surface temperature changes in the North sea and their causes. ICES J Mar Sci 53: 887-898

Bochkov YA (1982) Water temperature in the 0-200m layer in the Kola-Meridian in the Barents Sea, 1900-1981. Sb Nauchn Trud PINRO 46:113-122 (in Russian)

Cayan DR (1992) Latent and sensible heat flux anomalies over the northern oceans: the connection to monthly atmospheric circulation. J Clim 5:354-369

Cushing DH (1978) Biological effects of climatic change. Rapp P-V Reun Cons Int Explor Mer 173:107-116

Cushing DH (1982) Climate and fisheries. Academic Press, London
Cushing DH (1996) Towards a science of recruitment in fish populations. In: Kinne O (ed) Excellence in ecology, Book 7. Ecology Institute, Oldendorf

Cushing DH, Dickson RR (1976) The biological response in the sea to climatic changes. Adv Mar Biol 14:2-122

Deser C, Blackmon ML (1993) Surface climate variation over the North Atlantic ocean during winter: 1900-1989. J Clim 6:1743-1753

Dickson RR (1997) From the Labrador Sea to global change. Nature 386:649-650

Dickson RR (1999) All change in the Arctic. Nature 397:389-391

Dippner JW (1997a) SST anomalies in the North Sea in relation to the North Atlantic Oscillation and the influence on the theoretical spawning time of fish. Dt Hydrogr Z 49: 267-275

Dippner JW (1997b) Recruitment success of different fish stocks in the North Sea in relation to climate variability. Dt Hydrogr Z 49(2/3):277-293

Dippner JW (1999) Predicting cod recruitment from sea surface temperature data. In: Report of the workshop on Gadoid Stocks in the North Sea During the 1969s and 1970s. ICES CM 1999/C:15, Ref:C,G,ACFM

Ellertsen B, Fossum P, Solemdal P, Sundby S (1989) Relation between temperature and survival of eggs and first-feeding larvae of Northeast Arctic cod Gadus morhua L. Rapp P-V Reun Cons Int Explor Mer 191:209-219

Fromentin JM, Planque B (1996) Calanus and environment in the eastern North Atlantic. II. Influence of the North Atlantic Oscillation on C. finmarchicus and C. helgolandicus. Mar Ecol Prog Ser 134:111-118

Helland-Hansen B, Nansen F (1909) The Norwegian Sea. FiskDir Skr Ser HavUnders 2:1-360

Helle K, Bogstad B, Marshall CT, Michalsen K, Ottersen G, Pennington M (2000) An evaluation of recruitment indices for Arcto-Norwegian cod (Gadus morhua L.). Fish Res 993: $1-13$

Heyen H, Dippner JW (1998) Salinity variability in the German Bight in relation to climate variability. Tellus 50A: $545-556$

Hjort J (1914) Fluctuations in the great fisheries of northern Europe viewed in the light of biological research. Rapp P-V Reun Cons Int Explor Mer 20:1-228

Houghton RW (1996) Subsurface quasi-decadal fluctuations in the North Atlantic. J Clim 9:1361-1373

Hurrell JW (1995) Decadal trends in the North Atlantic Oscillation: regional temperatures and precipitation. Science 269:676-679

ICES (1965) Estimation of mortality rates. Anex to Arctic Fisheries Working Group. Report of meeting in Hamburg 18-23 January 1965. ICES Group Ref Rep Ser A 16:1-60

ICES (1993) Report of the Arctic fisheries working group. ICES CM 1993:1

Izhevskii GK (1964) Forecasting of oceanological conditions and the reproduction of commercial fish. Moskva Israel Progr Sci Transl, Jerusalem (translator: Pishcepromizdat, Moscow)

Kawamura R (1994) A rotated EOF analysis of global sea surface temperature variability with interannual and interdecadal scales. J Phys Oceanogr 24:707-715

Kröncke I, Dippner JW, Heyen H, Zeiss B (1998) Long-term changes in macrofaunal communities off Norderney (East Frisia, Germany) in relation to climate variability. Mar Ecol Prog Ser 167:25-36

Kushnir Y, Wallace JM (1989) Low-frequency variability in the northern hemisphere winter: geographical distribution, structure and time-scale dependence. J Atmos Sci 46: 3122-3142 
Lamb PJ, Peppler RA (1987) North Atlantic Oscillation: concept and an application. Bull Am Meteorol Soc 68: $1218-1225$

Livezey RE (1995) The evaluation of forecast. In: von Storch $\mathrm{H}$, Navarra A (eds) Analysis of climate variability. Springer-Verlag, Berlin, p 177-196

Loeng H (1989) The influence of temperature on some fish population parameters in the Barents Sea. J Northwest Atl Fish Sci 9:103-113

Loeng H, Blindheim J, Ådlandsvik B, Ottersen G (1992) Climatic variability in the Norwegian and Barents Seas. ICES Mar Sci Symp 195:52-61

Loeng H, Ozhigin V, Ådlandsvik B (1995a) Water fluxes through the Barents Sea. ICES CM 1995/Mini:10

Loeng H, Bjørke H, Ottersen G (1995b) Larval fish growth in the Barents Sea. In: Beamish RJ (ed) Climate change and northern fish populations. Can Spec Publ Fish Aquat Sci 121:691-698

Marshall J, Kushnir Y (1997) A 'white paper' on Atlantic climate variability. Massachusetts Institute of Technology, Cambridge. Available at: http://geoid.mit.edu/accp/avehtml.html

Michaelsen J (1987) Cross-validation in statistical climate forecast models. J Clim Appl Meteorol 26:1589-1600

Midttun L (1990) Surface temperatures in the Barents Sea. Polar Res 8:11-16

Moses T, Keladis GN, Diaz HF, Barry RG (1987) Characteristics and frequency of reversals in mean sea level pressure in the North Atlantic sector and their relationships to longterm temperature trends. J Climatol 7:13-30

Myers R (1998) When do environment-recruitment correlations work? Rev Fish Biol Fish 8:1-21

Nakken O (1994) Causes of trends and fluctuations in the Arcto-Norwegian cod stock. ICES Mar Sci Symp 198: 212-228

Namias J, Cayan DR (1981) Large-scale air-sea interactions and short-period climate fluctuations. Science 214: 869-878

Øiestad V (1994) Historic changes in cod stocks and cod fisheries: Northeast Arctic cod. ICES Mar Sci Symp 198:17-30

Ottersen G (1996) Environmental impact on variability in recruitment, larval growth and distribution of Arcto-Norwegian cod. PhD thesis, University of Bergen

Ottersen G, Loeng H (2000) Covariability in early growth and year-class strength of Barents Sea cod, haddock and herring: the environmental link. ICES J Mar Sci 57:339-348

Ottersen G, Sundby S (1995) Effects of temperature, wind and

Editorial responsibility: Hans von Storch,

Geesthacht, Germany spawning stock biomass on recruitment of Arcto-Norwegian cod. Fish Oceanogr 4:278-292

Ottersen G, Loeng H, Raknes A (1994) Influence of temperature variability on recruitment of cod in the Barents Sea. ICES Mar Sci Symp 198:471-481

Planque B, Fredou T (1999) Temperature and the recruitment of Atlantic cod (Gadus morhua). Can J Fish Aquat Sci 56: 2069-2077

Randa K (1982) Recruitment indices for the Arcto-Norwegian Cod for the period 1965-1979 based on the international 0-group fishery. ICES CM 1982/G:53

Randa K (1984) Abundance and distribution of 0-group ArctoNorwegian cod and haddock 1965-1982. In: Godø OR, Tilseth S (eds) Proceedings of the Soviet-Norwegian Symposium on reproduction and recruitment of Arctic Cod. Leningrad, 25-30 September 1983. Institute of Marine Research, Bergen, p 192-212

Saetersdal G, Loeng H (1987) Ecological adaptation of reproduction in Northeast Arctic Cod. Fish Res 253-270

Sirabella P, Giuliani A, Colosimo A, Dippner JW (2001) Deconvolving the climate effects on cod recruitment by principal component analysis and canonical correlation. Mar Ecol Prog Ser 216:213-222

Sundby S, Bjørke H, Soldal AV, Olsen, S (1989) Mortality rates during the early life stages and year-class strength of Northeast Arctic cod (Gadus morhua L.) Rapp P-V Reun Cons Int Explor Mer 191:351-358

Svendsen E, Aglen A, Iversen SA, Skagen DW, Smestad O (1995) Influence of climate on recruitment and migration of fish stocks in the North Sea. In: Beamish RJ (ed) Climate change and northern fish populations. Can Spec Publ Fish Aquat Sci 121:641-653

Tereshchenko VV (1996) Seasonal and year-to-year variations of temperature and salinity along the Kola meridian transect. ICES CM C:11

Trenberth KE, Paolino DA Jr (1980) The northern hemisphere SLP-dataset: trends, errors and discontinuities. Mon Weather Rev 112:1999-2015

von Storch H (1995) Spatial patterns: EOF and CCAs. In: von Storch H, Navarra A (eds) Analysis of climate variability. Springer-Verlag, Berlin, p 227-253

von Storch H, Zorita E, Cubasch U (1993) Downscaling of global climate change estimates to regional scales: an application to Iberian rainfall in wintertime. J Clim 6: $1161-1171$

Walker GT, Bliss EW (1932) World weather V. Mem R Meteorol Soc 4:53-84

Submitted: April 10, 2000; Accepted: December 24, 2000

Proofs received from author(s): May 11, 2001 